\title{
Volume of Neonatal Care and Survival without Disability at 2 Years in Very Preterm Infants: Results of a French National Cohort Study
}

Thomas Desplanches ${ }^{\mathrm{a}, \mathrm{b}}$, RM, MSc, Béatrice Blondel ${ }^{\mathrm{a}}, \mathrm{PhD}$, Andrei Scott Morgan ${ }^{\mathrm{a}}, \mathrm{MD}, \mathrm{PhD}$, Antoine Burguet $^{\mathrm{a}, \mathrm{c}}, \mathrm{MD}, \mathrm{PhD}$, Monique Kaminski ${ }^{\mathrm{a}}$, MSc, Bénédicte Lecomte ${ }^{\mathrm{d}}$, MD, Laetitia Marchand-Martin $^{\mathrm{a}}$, MSc, Jean-Christophe Rozée, MD, PhD, Paul Sagot ${ }^{\mathrm{b}}$, MD, PhD, Patrick Truffert $^{\mathrm{f}}, \mathrm{MD}, \mathrm{PhD}$, Jennifer Zeitlin ${ }^{\mathrm{a}}, \mathrm{PhD}$, Pierre-Yves Ancel ${ }^{\mathrm{a}, \mathrm{g}}, \mathrm{MD}, \mathrm{PhD}$, Jeanne Fresson ${ }^{\mathrm{a}, \mathrm{h}}$, $\mathrm{MD}, \mathrm{PhD}$.

Affiliations: ${ }^{a}$ Obstetrical, Perinatal, and Pediatric Epidemiology Team, Epidemiology and Biostatistics Sorbonne Paris Cité Research Center (U1153), INSERM, Paris, France; Paris Descartes University, Paris, France. ${ }^{b}$ CHRU Dijon, Department of gynecology, obstetrics, fetal medicine and infertility, Dijon, France; University of Burgundy and Franche-Comté, Dijon, France. ${ }^{c}$ Department of Neonatal Pediatrics, Dijon University Hospital, Dijon, France. ${ }^{d}$ Estaing University Hospital, Clermont-Ferrand, France. ${ }^{e}$ Pediatric Intensive Care Unit, Mothers' and Children's Hospital, Nantes Teaching Hospital, Nantes, France. ${ }^{\mathrm{f}}$ Neonatal Intensive Care Unit, Jeanne de Flandre Hospital, CHRU Lille, Lille, France. ${ }^{\mathrm{g}}$ Clinical Research Unit, Center for Clinical Investigation P1419, CHU Cochin Broca Hôtel-Dieu, Paris, France. h CHRU Nancy, Department of medical information, Obstetrics Department, Nancy, France

Address correspondence to: Thomas Desplanches - thomas.desplanches@inserm.fr. CHU-DIJON 4 boulevard de Lattre de Tassigny 21000 Dijon. 0647561353.

List of key words: Neonatal Intensive Care Unit, neuromotor and sensory disabilities, regionalization, evidence-based practices.

Supported by the French Institute of Public Health Research/Institute of Public Health and its partners the French Health Ministry, the National Institute of Health and Medical Research, the National Cancer Institute and the National Solidarity Fund for Autonomy; the National Research Agency through the French Equipex Program of Investments in the Future (ANR-11-EQPX0038); the PremUp Foundation and Fondation pour la Recherche Médicale. The authors declare no conflicts of interest.

Objectives: To investigate the relation between neonatal intensive care init (NICU) volume and survival, neuromotor and sensory disabilities at 2 years in very preterm infants. 
Study design: The EPIPAGE-2 national prospective population-based cohort study was used to include 2447 babies born alive in 66 level III hospitals between 24 and 30 completed weeks of gestation in 2011. The outcome was survival without disabilities (levels 2-5 of the Gross Motor Function Classification System for cerebral palsy with or without unilateral or bilateral blindness or deafness). Units were grouped in quartiles according to volume, defined as the annual admissions of very preterm babies. Multivariate logistic regression analyses with population average models were used.

Results: Survival at discharge was lower in hospitals with lower volumes of neonatal activity (adjusted Odds Ratio 0.55, 95\% Confidence Interval 0.33-0.91). Survival without neuromotor and sensory disabilities at two years increased with hospital volume, from $75 \%$ to $80.7 \%$ in the highest volume units. After adjustment for gestational age, small for gestational age, sex, maternal age, infertility treatment, multiple pregnancy, principal cause of prematurity, parental socioeconomic status and mother's country of birth, survival without neuromotor or sensory disabilities was significantly lower in hospitals with a lower volume of neonatal activity (adjusted Odds Ratio: $0.60,95 \%$ confidence interval: $0.38-0.95)$ than in the highest quartile hospitals.

Conclusions: These results suggest that lower NICU volume is associated with lower survival without an increase in disabilities at 2 years. These results could be useful to generate improvements of perinatal regionalization.

Studies on regionalization of care have shown that mortality and severe neonatal morbidity of very low birth weight (VLBW) or very preterm (VPT) infants is lower when birth occurs at highly specialized hospitals. ${ }^{1,2}$ In most developed countries, it is recommended that 
VLBW and VPT infants be born in specialized hospitals, generally designated as level III NICU hospitals ${ }^{3-6}$.

Several studies have used hospital volume as an indicator of quality of care, and found that neonatal care at high-volume centers was associated with lower in-hospital mortality of VLBW and VPT infants ${ }^{7-12}$. However, some of these studies ${ }^{11,12}$ also found a higher rate of severe neonatal morbidity in high volume hospitals, suggesting that their survivors may be at increased risk of disability in survivors. Studying longer term outcomes at 2 years is needed to determine whether the improvement in survival is followed by an increase in disabilities, providing valuable data for policy makers. In addition, it is worth testing whether these associations, seen primarily in the USA and in VLBW babies, exist in other countries and in VPT babies.

Perinatal regionalization has been in place in France since $1998{ }^{13}$. Level III hospitals are defined as the highest level of care for preterm birth, and must have a Neonatal Intensive Care Unit (NICU), with the permanent presence of a qualified pediatrician trained in neonatology ${ }^{14}$. In 2011, more than $80 \%$ of preterm births at $24^{+0}$ to $30^{+6}$ completed weeks of gestation were managed in a level III hospital ${ }^{15}$. Previous French studies on regionalization are relatively outdated ${ }^{16,17}$, and none has investigated the effect of hospital volume.

Our objectives were to investigate the association of hospital volume with survival at discharge without severe neonatal morbidity, and survival at two years corrected age without neuromotor or sensory disabilities, among infants born at $24^{+0}$ to $30^{+6}$ weeks gestation in tertiary hospitals. We hypothesized that there would be higher survival without disability in VPT children born in hospitals that managed a high volume of premature newborns. We also investigated to 
what extent the implementation of evidence-based practices varied by NICU volumes, potentially contributing to the health outcomes of VPT children.

\section{Methods}

The prospective population-based EPIPAGE 2 cohort (Etude Epidémiologique sur les Petits Âges Gestationnels) included all births occurring between 22 and 34 completed weeks' gestation in the 546 maternity units of 25 French regions from March to December in 2011. Recruitment lasted 8 months for infants born at 22 to 26 weeks and 6 months for those born at 27 to 31 weeks gestation. At 2 years corrected age, clinical data were collected through two standardized questionnaires: one completed by the referring pediatrician and the other by the parents. Details about ethical approval, the design and methods have been described previously 18,19

We restricted our analyses to babies who were born alive in tertiary centers between 24 and 30 weeks gestation. We excluded neonates born after 30 weeks because the French recommendations allow for the management of these births in lower level hospitals. Newborns with lethal malformations (eg, anencephaly, and bilateral renal agenesis) or antenatal decision not to resuscitate were also excluded. All survivors were enrolled in follow-up if parents consented at 2 years corrected age.

Volume was defined as the total number of babies below 31 weeks gestation admitted to each hospital NICU during 2011. This number was obtained from the national hospital discharge database ("Programme de médicalisation du système d'information" used to determine the activity-based funding of French hospitals). We created four groups of hospitals using the $25^{\text {th }}$, $50^{\text {th }}$ and $75^{\text {th }}$ percentiles of volume. Hospitals in the highest quartile (Q4) were defined as high 
volume units. Infants were allocated to the first level 3 unit in which they were hospitalized for 48 consecutive hours, or, when infants died in the delivery room, the NICU in connection with the obstetric unit.

Studied outcomes were survival at discharge, survival at discharge without severe neonatal morbidity, survival without sensorimotor disabilities at 2 years of age and psychomotor development outcome at 2 years. Severe neonatal morbidity was defined by one or more of the following complications: severe bronchopulmonary dysplasia (BPD), defined as administration of oxygen for at least 28 days plus need for $30 \%$ or more oxygen and/or mechanical ventilation or continuous positive airway pressure at 36 weeks postmenstrual age, severe intraventricular hemorrhage, defined as IVH associated with ventricular dilation (grade III, IV) and/or intraparenchymal hemorrhage, cystic periventricular leukomalacia, Bell's stage II or III necrotizing enterocolitis, and stage 3 or higher retinopathy of prematurity (ROP) ${ }^{18}$.

Neuromotor and sensory disabilities included two outcomes: cerebral palsy and sensory disability. We used the diagnostic criteria previously established by the Surveillance of Cerebral Palsy in Europe (SCPE) network to define cerebral palsy ${ }^{20}$, and the five level Gross Motor Function Classification System (GMFCS) to classify motor ability ${ }^{21}$. A child had a disability if he/she had cerebral palsy, GMFCS level 2-5, or unilateral or bilateral deafness or blindness. Psychomotor development outcome at two years was assessed using the second version of the Ages and Stages Questionnaire (ASQ) ${ }^{22}$, and we analyzed the data if parents filled out this document when their child was between 22 and 26 months corrected age and if the child did not have cerebral palsy or sensory impairments. ASQ evaluates five domains of child development: communication, gross motor, fine motor, problem-solving and personal-social. We considered a 
child as below threshold if he/she scored lower than 2 standard deviations from the mean in at least one domain ${ }^{22}$.

We considered the following maternal characteristics: maternal age, maternal country of birth, and parents' socioeconomic status (the highest occupational status of the mother and the father, or mother only if a single parent). Pregnancy characteristics were: parity, infertility treatment, multiple pregnancy, antenatal steroids, antenatal transfer, hospital admission less than 24 hours before delivery, principal cause of prematurity (classified as preterm labor, preterm premature rupture of membranes (PPROM), hypertensive disorders or abruptio placentae, fetal growth retardation (FGR), or other ${ }^{23}$ ) and mode of delivery.

Infant characteristics considered were gestational age at delivery (in completed weeks' gestation), sex, small for gestational age (SGA) using the French intrauterine growth curves ${ }^{24}$, admission temperature (within 12 hours after birth), surfactant $(0,1$ or 2 doses) for infants admitted to NICU and postnatal transfer (including repatriation transfers).

We also investigated three evidence-based practices which were recommended in the early 2010's and were identified as improving survival without severe neonatal morbidity in VPT infants ${ }^{25}$ : any administration of antenatal corticosteroids before delivery; effective prevention of hypothermia defined as temperature on admission of $36^{\circ} \mathrm{C}$ or more; and surfactant used within two hours or early nasal continuous positive airway pressure (CPAP) for infants born before 28 WG for infants admitted to NICU.

This study was approved by the National Data Protection Authority (CNIL no.911009) and by the appropriate ethics committees (Consultative Committee on the Treatment of Data on Personal Health for Research Purposes - reference no. 10.626, Committee for the Protection of People Participating in Biomedical Research - reference CPP SC-2873). 


\section{Statistical analyses}

Univariate analyses were performed to describe the population characteristics and evidence-based practices according to hospital volume, using Chi-squared tests. Statistical significance was set at a two-tailed test with $P<.05$. We used weighted percentages and gestational age adjustments in the multivariable analyses to account for differences in sampling times between gestational age groups.

Multivariate logistic regression analyses with population average models were used to analyze the association between hospital volume and the study outcomes taking into account clinical and healthcare factors known to affect outcomes and hospital volume. These factors were sex, gestational age, small for gestational age $\left(<10^{\text {th }} \text { percentile }\right)^{24}$, maternal age, infertility treatment, principal cause of prematurity, multiple or singleton pregnancy, parental socioeconomic status and mother's country of birth. We used a generalized estimating equation (GEE) approach to take into consideration the clustering of births within hospitals ${ }^{26}$.

To check the robustness of the results, two sensitivity analyses were performed. First, for children aged between 24 and 25 weeks' gestation, there was no consensus about active management across French regions in $2011^{18,27}$, and the decision to initiate resuscitation at birth varied greatly between hospitals. These children are considered to be on the edge of viability in France ${ }^{28,29}$. Therefore, we conducted analysis on a restricted population of $26-30$ weeks for whom active resuscitation was commonly initiated in France ${ }^{30}$. Secondly, as mortality is higher in French overseas departments and territories ${ }^{31}$, an analysis was conducted on only the newborns born in metropolitan France. Finally, because newborns were potentially transferred to another level III unit after birth, we performed a sensitivity analysis by excluding newborns hospitalized in more than one level III unit. 
Survival at discharge was reported for all live births. In contrast, to account for dropouts and missing information, survival without severe neonatal morbidity at discharge and survival without neuromotor and sensory disability at 2 years corrected age was reported after multiple imputation. Among survivors, results are reported for both complete cases and all cases after multiple imputation. Missing data were imputed by chained equations using the SAS "MI" procedure ${ }^{32}$. Imputation model variables included maternal, antenatal and neonatal characteristics (maternal age, parity, parental socioeconomic status, country of birth, infertility treatment, principal cause of prematurity, antenatal steroids, multiple pregnancy, caesarean section, SGA, gestational age, sex, Apgar score, surfactant, admission temperature), and outcomes (severe neonatal morbidities, cerebral palsy, neuromotor or sensory disabilities, and ASQ). For ASQ, missing domains were separately imputed to account for partially completed questionnaires and ASQ score was then estimated using the imputed domain specific data for infants without cerebral palsy, deafness, or blindness. Binary variables were imputed using logistic regression and socioeconomic data were imputed using multinomial models. We generated 50 independent imputed datasets with 30 iterations each. Estimates were pooled according to Rubin's rule ${ }^{33}$. Further details are available in Table I (available at www.jpeds.com). All analyses were carried out with SAS v9.4 software.

\section{Results}

Admissions per year were <55 (Quartile 1, Q1), 55-79 (Q2), 80-109 (Q3) and > $110(\mathrm{Q} 4)$, with a range of 14 to 174 very preterm babies admitted per hospital. Hospital characteristics are presented in Table 2 (available at www.jpeds.com). Of the high-volume hospitals, $87 \%$ were part of a University system and $80 \%$ performed neonatal surgery. 
In total, 2447 infants were born between 24 and 30 weeks gestation in 66 level III hospitals (Figure 1; available at www.jpeds.com). Table 3 and Table 4 provide maternal and neonatal characteristics according to hospital volume. Q4 hospitals had higher proportions of women born outside France and of women from a higher socioeconomic status.

Only $10 \%$ of newborns were admitted to low volume units (Q1). In this group, significantly fewer women received fertility treatment or were transferred before delivery. Moreover, compared with infants born in Q4 hospitals, infants born in Q1 hospitals less frequently received antenatal steroids or surfactant, and presented more frequently with hypothermia. The principle cause of preterm delivery, gestational age, SGA and sex did not differ according to hospital volume.

The proportion of infants receiving all three evidence-based interventions increased significantly with hospital volume, from $49.8 \%$ in Q1 hospitals to $64.0 \%$ in Q4 hospitals. The proportion of infants receiving surfactant therapy or early nasal CPAP did not significantly differ according to hospital volume (Figure 2).

Survival at discharge was lower in Q1 hospitals (adjusted odds ratio (aOR) 0.56, 95\% CI 0.33-0.91, Table 5). The percentages of severe neonatal morbidity were significantly higher in the two top quartiles (Table 6; available at www.jpeds.com). Survival without severe neonatal morbidity did not differ with hospital volume (Table 5).

A total of 2116 infants were discharged home, 13 died after discharge and 104 children did not participate in follow-up. In all, 1999 children were included in follow-up; the medical questionnaire for 2 years corrected age was completed for 1764 children (83.4\%) and the ASQ at 22-26 months corrected age was available for 1232 (58.6\%) (Figure 1). Data were more frequently missing from children born to families with low socioeconomic status (Table 1). 
Survival without neuromotor or sensory disabilities at two years was lower in Q1, Q2, Q3 hospitals vs. Q4 hospitals, but the aOR was only significantly lower in Q1 hospitals (aOR 0.60, 95\% CI 0.38-0.95) (Table 5). Results from the sensitivity analyses were similar (Table 7; available at www.jpeds.com). Our findings were also similar when we excluded newborns $(n=49)$ who were hospitalized in several level III units (Data not shown). Among surviving infants, we found no significant difference in the incidence of neuromotor or sensory disabilities or ASQ below threshold according to hospital volume (Table 8; available at www.jpeds.com).

\section{Discussion}

In this population-based cohort study, we found that infants born between 24 and 30 weeks gestation and admitted to low volume neonatal units had consistently lower aOR for survival without neuromotor or sensory disabilities at 2 years corrected age vs. high volume units. Neuromotor and sensory disabilities and low ASQ score did not vary with hospital volume.

The EPIPAGE-2 study is based on a large national prospective cohort. Numerous maternal and neonatal characteristics were collected, thus increasing the robustness of the adjustments. A robust system of verification was used involving study statisticians and local investigators with access to original care notes. We used the volume of admission of VPT newborns in NICU as the exposure variable because this variable is a more relevant and accurate indicator of medical activity in the management of preterm infants than other indicators such as obstetric volume. Our exposure variable was based on reliable data from the national hospital discharge database ${ }^{34}$. A GEE approach was used to take into consideration the clustering of births within hospitals, and sensitivity analyses were performed to account for possible variations in management of VPT newborns between perinatal networks. Only live births in level III 
hospitals were included; this selection limits the generalization of our results for all neonates born between 24 and 30 weeks, but it has the advantage of analyzing relatively similar services (staff and equipment) and relatively similar newborns not transferred after birth.

The main limitation of our study is the follow-up rate at two years, which was lower than in other recent cohort studies on extremely preterm births ${ }^{35-37}$, but these studies included fewer infants. The proportion of children lost to follow-up was higher in families with low socioeconomic status ${ }^{19}$ and in hospitals with low neonatal activity, but the neonatal characteristics of these children were similar to those followed-up. Multiple imputation was used to account for missing data.

The quality of care received by newborns during their successive neonatal hospitalizations until discharge may have affected the relationship between hospital volume in the initial hospital and outcomes even though there were fewer postnatal transfers among children born in low volume hospitals.

If volume is an indicator of the experience and organization of a service, it would be better to use the volume before inclusion (2010), but the collection of gestational age in the national hospital discharge database only became mandatory in 2011. NICU volume may be a surrogate for other hospital characteristics or case-mix that contribute to the risk of disabilities. To limit this effect, children with lethal malformations were excluded, and numerous risk factors were introduced in the models.

In our study, a large proportion of NICUs had a high number of admissions, making it difficult to distinguish effects between NICUs with over 55 admissions of VPT newborns per year. In addition, our sample was not large enough to detect moderate differences in the intermediate groups, which might have clinical significance. We were also unable to identify an 
admission threshold in the lowest-volume NICUs for which survival without disability would be significantly lower. One previous study ${ }^{7}$ used modeling techniques to select the thresholds for investigation, but this required a much larger sample size, and they did not present data on longer-term neurodevelopment.

Another limitation is the lack of data on maternal distance to the closest level III maternity unit. However, low-volume NICUs (Q1) are not always located in isolated areas; for example, only 3 out of the 40 perinatal networks existing in 2011 had a low volume NICU as the sole NICU in the network. In addition, outborn infants are most affected by distance ${ }^{38,39}$, but our study did not include this population.

Previous studies on the effect of volume on neonatal care have mainly used retrospective cohorts ${ }^{7,11,12}$, which had the advantage of large populations, but only studied in-hospital mortality and severe neonatal morbidity. These studies found that hospitalization in the top volume quartile was associated with a decreased risk of death. However, improved survival can potentially lead to an increase in the number of vulnerable infants developing neonatal and longterm complications. We found a trend toward increased severe neonatal morbidity in our study, and two other studies have shown an increased risk of BPD and ROP treatment in large units ${ }^{11,12}$. Our results suggest, however, that neuromotor and sensory disabilities at 2 years and psychomotor development did not differ with neonatal unit volume.

To understand the differences in survival between hospitals, factors such as number of beds, university status and level of care have been explored, but none were shown to be associated with survival ${ }^{9,10}$. On the contrary, the association with NICU volume found in several countries shows the importance of this factor. A high volume of activity may be associated with other beneficial factors such as better coordination of obstetric-pediatric care, more experienced 
caregiving staff, or better implementation of clinical guidelines, as our study suggests. The three clinical practices investigated in our study can be considered indirect markers of the quality of perinatal care because they have been strongly recommended since 2011 and involve both obstetrical (antenatal steroids) and neonatal practices (prevention of hypothermia and surfactant or early nasal CPAP). The large variability of clinical practices across countries ${ }^{40,41}$ suggests that other clinical practices should be considered in order to understand which practices have a major impact on infant health. Evidence-based practices should be encouraged through appropriate training and evaluation in particular in the smallest volume hospitals. Morbidity and mortality reviews and the clinical pathway, as described by Rotter et al, are methods for evaluating and improving practices and could help obstetrical and neonatal teams improve the management of VPT infants. ${ }^{42}$

Our results suggest that volume has an impact on survival without neuromotor and sensory disabilities mainly in the lowest activity units. This raises the question of whether it is necessary to establish volume thresholds for the admission of very preterm births in neonatal units, as recommended or enforced for level III units since 2003 in Belgium, Germany (50 VLBW), the Netherlands (200 total admissions) ${ }^{43}$ and in the United Kingdom (100 VLBW) ${ }^{44}$. However, closing the lowest activity NICUs could impede or delay maternal transfers, thereby increasing the number of infants born outside level III hospitals ${ }^{39}$. Policy decisions regarding perinatal regionalization must therefore weigh the respective impact of NICU volume and the geographic access to these units, as has been done in limited-access zones ${ }^{45}$.

In conclusion, our study suggests that the higher survival rate in the highest volume neonatal units was not followed by a higher risk of disability at two years. Further studies should focus on 
why survival at discharge for very preterm infants admitted to small-volume neonatal units is significantly lower. Our results add new information to the ongoing debate on the optimal regionalization of perinatal care. 


\section{List of abbreviations:}

ASQ: Ages and Stages Questionnaire

BPD: bronchopulmonary dysplasia

CPAP: continuous positive airway pressure

EPIPAGE 2: Etude EPIdémiologique sur les Petits Âges GEstationnels

FGR: Fetal Growth Retardation

GEE: Generalized Estimating Equation

GMFCS: Gross Motor Function Classification System

NICU: Neonatal Intensive Care Units

OR: Odds Ratio

PPROM: Preterm Premature Rupture of Membranes

ROP: Retinopathy of Prematurity

SCPE: Surveillance of Cerebral Palsy in Europe

SGA: Small for Gestational Age

VLBW: very low birth weight

VPT: very preterm

WG: Weeks of Gestation

Acknowledgments: We thank Dr Aurélie Bannay for providing the additional data from the national hospital discharge database. We are grateful for the participation of all families of preterm infants in the EPIPAGE-2 cohort study and for the cooperation of all maternity and neonatal units in France. We thank parents' associations (SOS Prema, Collectif Interassociatif Autour de la NaissancE [CIANE], Jumeaux et Plus, Soins Palliatifs et Accompagnement en MAternite [SPAMA] for their overwhelming support and their involvement in the dissemination of the results. We thank the EPIPAGE-2 study group for its substantial contribution to the conception, design, and acquisition of data. 


\section{References}

1. Lasswell SM, Barfield WD, Rochat RW, Blackmon L. Perinatal regionalization for very low-birth-weight and very preterm infants: a meta-analysis. JAMA. 2010;304(9):9921000.

2. Rashidian A, Omidvari AH, Vali Y, et al. The effectiveness of regionalization of perinatal care services--a systematic review. Public Health. 2014;128(10):872-885.

3. Nowakowski L, Barfield WD, Kroelinger CD, et al. Assessment of state measures of riskappropriate care for very low birth weight infants and recommendations for enhancing regionalized state systems. Matern Child Health J. 2012;16(1):217-227.

4. American College of Obstetricians, Gynecologists, Society for Maternal-Fetal Medecine, et al. Levels of maternal care. Am J Obstet Gynecol. 2015;212(3):259-271.

5. Zeitlin J, Papiernik E, Breart G, Group E. Regionalization of perinatal care in Europe. Semin Neonatol. 2004;9(2):99-110.

6. Blondel B, Papiernik E, Delmas D, et al. Organisation of obstetric services for very preterm births in Europe: results from the MOSAIC project. BJOG. 2009;116(10):13641372.

7. Rogowski JA, Horbar JD, Staiger DO, Kenny M, Carpenter J, Geppert J. Indirect vs direct hospital quality indicators for very low-birth-weight infants. JAMA. 2004;291(2):202-209.

8. Phibbs CS, Baker LC, Caughey AB, Danielsen B, Schmitt SK, Phibbs RH. Level and volume of neonatal intensive care and mortality in very-low-birth-weight infants. $N$ Engl J Med. 2007;356(21):2165-2175. 
9. Chung JH, Phibbs CS, Boscardin WJ, Kominski GF, Ortega AN, Needleman J. The effect of neonatal intensive care level and hospital volume on mortality of very low birth weight infants. Med Care. 2010;48(7):635-644.

10. Esser M, Lack N, Riedel C, Mansmann U, von Kries R. Relevance of hospital characteristics as performance indicators for treatment of very-low-birth-weight neonates. Eur J Public Health. 2014;24(5):739-744.

11. Watson SI, Arulampalam W, Petrou S, et al. The effects of designation and volume of neonatal care on mortality and morbidity outcomes of very preterm infants in England: retrospective population-based cohort study. BMJ Open. 2014;4(7):e004856.

12. Jensen EA, Lorch SA. Effects of a Birth Hospital's Neonatal Intensive Care Unit Level and Annual Volume of Very Low-Birth-Weight Infant Deliveries on Morbidity and Mortality. JAMA Pediatr. 2015;169(8):e151906.

13. Zeitlin J, Ancel PY, Delmas D, et al. Changes in care and outcome of very preterm babies in the Parisian region between 1998 and 2003. Arch Dis Child Fetal Neonatal Ed. 2010;95(3):F188-193.

14. Ministère de l'emploi et de la solidarité. Décret n98-899 et n98-900 du 9 octobre 1998. Journal officiel de la république française. 1998;15343.

15. Ancel PY, Goffinet F, Group E-W, et al. Survival and morbidity of preterm children born at 22 through 34 weeks' gestation in France in 2011: results of the EPIPAGE-2 cohort study. JAMA Pediatr. 2015;169(3):230-238.

16. Vieux R, Fresson J, Hascoet JM, et al. Improving perinatal regionalization by predicting neonatal intensive care requirements of preterm infants: an EPIPAGE-based cohort study. Pediatrics. 2006;118(1):84-90. 
17. Veit-Sauca B, Boulahtouf H, Mariette JB, et al. [Regionalization of perinatal care helps to reduce neonatal mortality and morbidity in very preterm infants and requires updated information for caregivers]. Arch Pediatr. 2008;15(6):1042-1048.

18. Ancel PY, Goffinet F, Group EW. EPIPAGE 2: a preterm birth cohort in France in 2011. BMC Pediatr. 2014;14:97.

19. Pierrat V, Marchand-Martin L, Arnaud C, et al. Neurodevelopmental outcome at 2 years for preterm children born at 22 to 34 weeks' gestation in France in 2011: EPIPAGE-2 cohort study. BMJ. 2017;358:j3448.

20. Surveillance of cerebral palsy in Europe (SCPE): a collaboration of cerebral palsy surveys and registers. Dev Med Child Neurol. 2000; 42(12):816-824.

21. Ghassabian A, Sundaram R, Bell E, Bello SC, Kus C, Yeung E. Gross Motor Milestones and Subsequent Development. Pediatrics. 2016;138(1).

22. Squire J, Twombly E, Bricker D, Potter L. ASQ-3: User's guide. Baltimore Brookes Publishing: Ages \& Stages Questionnaires, Third Edition (ASQ-3TM). 2009.

23. Delorme P, Goffinet F, Ancel PY, et al. Cause of Preterm Birth as a Prognostic Factor for Mortality. Obstet Gynecol. 2016;127(1):40-48.

24. Ego A, Prunet C, Lebreton E, et al. [Customized and non-customized French intrauterine growth curves. I - Methodology]. J Gynecol Obstet Biol Reprod (Paris). 2016;45(2):155164.

25. Zeitlin J, Manktelow BN, Piedvache A, et al. Use of evidence based practices to improve survival without severe morbidity for very preterm infants: results from the EPICE population based cohort. BMJ. 2016;354:i2976. 
26. Hubbard AE, Ahern J, Fleischer NL, et al. To GEE or not to GEE: comparing population average and mixed models for estimating the associations between neighborhood risk factors and health. Epidemiology. 2010;21(4):467-474.

27. Diguisto C, Goffinet F, Lorthe E, et al. Providing active antenatal care depends on the place of birth for extremely preterm births: the EPIPAGE 2 cohort study. Arch Dis Child Fetal Neonatal Ed. 2017;102(6):F476-F482.

28. Seri I, Evans J. Limits of viability: definition of the gray zone. J Perinatol. 2008;28 Suppl $1: S 4-8$.

29. Pignotti MS, Donzelli G. Perinatal care at the threshold of viability: an international comparison of practical guidelines for the treatment of extremely preterm births. Pediatrics. 2008;121(1):e193-198.

30. Moriette G, Rameix S, Azria E, et al. [Very premature births: Dilemmas and management. Part 1 . Outcome of infants born before 28 weeks of postmenstrual age, and definition of a gray zone]. Arch Pediatr. 2010;17(5):518-526.

31. Blondel B, Raynaud P. 2016 French National Perinatal Survey. http://www.epopéinserm.fr/en/grandes-enquetes/enquetes-nationales-perinatales. (Accessed February 2019).

32. White IR, Royston P, Wood AM. Multiple imputation using chained equations: Issues and guidance for practice. Stat Med. 2011;30(4):377-399.

33. Rubin DB, Schenker N. Multiple imputation in health-care databases: an overview and some applications. Stat Med. 1991;10(4):585-598. 
34. Quantin C, Cottenet J, Vuagnat A, et al. [Quality of perinatal statistics from hospital discharge data: comparison with civil registration and the 2010 National Perinatal Survey]. J Gynecol Obstet Biol Reprod (Paris). 2014;43(9):680-690.

35. Doyle LW, Roberts G, Anderson PJ, Victorian Infant Collaborative Study G. Outcomes at age 2 years of infants < 28 weeks' gestational age born in Victoria in 2005. J Pediatr. 2010;156(1):49-53 e41.

36. Serenius F, Kallen K, Blennow M, et al. Neurodevelopmental outcome in extremely preterm infants at 2.5 years after active perinatal care in Sweden. JAMA. 2013;309(17):1810-1820.

37. Younge N, Goldstein RF, Bann CM, et al. Survival and Neurodevelopmental Outcomes among Periviable Infants. N Engl J Med. 2017;376(7):617-628.

38. Amer R, Moddemann D, Seshia M, et al. Neurodevelopmental Outcomes of Infants Born at <29 Weeks of Gestation Admitted to Canadian Neonatal Intensive Care Units Based on Location of Birth. J Pediatr. 2018;196:31-37 e31.

39. Pilkington H, Blondel B, Papiernik E, et al. Distribution of maternity units and spatial access to specialised care for women delivering before 32 weeks of gestation in Europe. Health Place. 2010;16(3):531-538.

40. Adams M, Bassler D, Bucher HU, et al. Variability of Very Low Birth Weight Infant Outcome and Practice in Swiss and US Neonatal Units. Pediatrics. 2018;141(5).

41. Cummings JJ, Marlow N. Reducing Variations in Neonatal Outcomes: Look at Practices, Systems, and the Patient. Pediatrics. 2018;141(5). 
42. Rotter T, Kinsman L, James E, et al. Clinical pathways: effects on professional practice, patient outcomes, length of stay and hospital costs. Cochrane Database Syst Rev. 2010(3):CD006632.

43. Van Reempts P, Gortner L, Milligan D, et al. Characteristics of neonatal units that care for very preterm infants in Europe: results from the MOSAIC study. Pediatrics. 2007;120(4):e815-825.

44. British association of perinatal medicine. Optimal Arrangements for Neonatal Intensive Care Units in the UK including guidance on their medical staffing (2014). Available at https://www.bapm.org/resources/optimal-arrangements-neonatal-intensive-care-units-ukincluding-guidance-their-medical (accessed February 2019).

45. Neto MT. Perinatal care in Portugal: effects of 15 years of a regionalized system. Acta Paediatr. 2006;95(11):1349-1352. 


\section{Figure legend:}

Figure 1: Flow chart of study population

ASQ: Ages and Stages Questionnaire

Figure 2: Evidence-based interventions according to hospital volume among infants of $24^{+0}$ to $30^{+6}$ weeks gestation admitted to neonatal care.

CPAP=Continuous Positive Airway Pressure. Q: Quartile.

Chi-squared test: $\mathrm{p}<0.05$ for antenatal steroids, prevention hypothermia, and all three interventions. 
Table 3: Maternal and pregnancy characteristics according to hospital volume.

\begin{tabular}{|c|c|c|c|c|c|}
\hline \multirow[b]{3}{*}{ Number $(\%)$ of mothers } & \multicolumn{4}{|c|}{ Hospital volume* } & \multirow{3}{*}{$p$} \\
\hline & $<55(\mathrm{Q} 1)$ & $55-79(\mathrm{Q} 2)$ & 80-109 (Q3) & $\geq 110(\mathrm{Q} 4)$ & \\
\hline & $\mathrm{N}=213(10.5 \%)$ & $\mathrm{N}=459(22.2 \%)$ & $\mathrm{N}=598(29.1 \%)$ & $\mathrm{N}=799(38.3 \%)$ & \\
\hline \multicolumn{6}{|l|}{ Maternal characteristics, $\mathrm{n}(\%)^{\S}$} \\
\hline Maternal age (years) & & & & & 0.18 \\
\hline$<25$ & $44(20.5)$ & $96(20.6)$ & $137(22.7)$ & $132(16.6)$ & \\
\hline $25-34$ & $119(55.8)$ & $265(57.7)$ & $326(54.7)$ & $482(60.2)$ & \\
\hline$\geq 35$ & $50(23.7)$ & $98(21.7)$ & $135(22.6)$ & $185(23.2)$ & \\
\hline Mother born outside of France & $40(19.2)$ & $112(25.1)$ & $112(21.0)$ & $194(27.1)$ & 0.03 \\
\hline Socioeconomic status & & & & & 0.008 \\
\hline Professional/ Intermediate & $74(36.0)$ & $168(39.0)$ & $209(38.2)$ & $327(43.9)$ & \\
\hline Other & $117(59.1)$ & $237(54.6)$ & $309(56.7)$ & $408(53.8)$ & \\
\hline Not employed & $19(4.9)$ & $28(6.3)$ & $29(5.1)$ & $17(2.3)$ & \\
\hline Nulliparous women & $112(54.6)$ & $223(51.7)$ & $285(51.0)$ & $420(55.6)$ & 0.34 \\
\hline Infertility treatment & $21(9.7)$ & $55(12.0)$ & $72(12.4)$ & $136(17.3)$ & 0.001 \\
\hline Doses of antenatal steroids & & & & & 0.0001 \\
\hline 0 & $37(18.4)$ & $81(17.8)$ & $78(13.2)$ & $59(7.6)$ & \\
\hline 1 & $37(17.8)$ & $61(14.0)$ & $90(15.0)$ & $130(16.5)$ & \\
\hline 2 & $128(63.8)$ & $296(68.2)$ & $411(71.8)$ & $584(75.8)$ & \\
\hline Singleton & $180(84.9)$ & $358(78.1)$ & $484(80.7)$ & $632(79.2)$ & 0.19 \\
\hline Antenatal Transfer & $99(46.8)$ & $213(48.2)$ & $362(60.7)$ & $510(63.7)$ & 0.001 \\
\hline $\begin{array}{l}\text { Admission less than } 24 \text { hours before } \\
\text { delivery }\end{array}$ & $103(47.7)$ & $238(52.2)$ & $310(51.6)$ & $426(53.0)$ & 0.4 \\
\hline Principal cause of preterm delivery & & & & & 0.8 \\
\hline Preterm labor & $80(36.3)$ & $160(34.0)$ & $209(34.1)$ & $295(36.2)$ & \\
\hline pPROM & $59(28.2)$ & $130(27.7)$ & $155(25.6)$ & $230(27.9)$ & \\
\hline $\begin{array}{l}\text { Hypertensive disorders or } \\
\text { placental abruption }\end{array}$ & $53(25.4)$ & $118(26.7)$ & $161(27.7)$ & $181(23.7)$ & \\
\hline Fetal Growth Retardation & $11(5.5)$ & $31(7.2)$ & $34(6.1)$ & $44(5.9)$ & \\
\hline Other circumstances & $10(4.6)$ & $20(4.4)$ & $39(6.5)$ & $49(6.3)$ & \\
\hline Cesarean delivery & $139(66.1)$ & $289(66.0)$ & $406(69.2)$ & $515(66.8)$ & 0.68 \\
\hline
\end{tabular}

* Annual number of admissions of newborns under 31 weeks.

pPROM: Preterm Premature Rupture of Membranes. 
Table 4: Neonatal characteristics according to hospital volume.

\begin{tabular}{|c|c|c|c|c|c|}
\hline \multirow[b]{3}{*}{ Number $(\%)$ of newborns } & \multicolumn{4}{|c|}{ Hospital volume* } & \multirow{3}{*}{$p$} \\
\hline & $<55(\mathrm{Q} 1)$ & $55-79(\mathrm{Q} 2)$ & 80-109 (Q3) & $\geq 110(\mathrm{Q} 4)$ & \\
\hline & $\mathrm{N}=243(10.1 \%)$ & $\mathrm{N}=552(22.6 \%)$ & $\mathrm{N}=700(28.8 \%)$ & $\mathrm{N}=952(38.5 \%)$ & \\
\hline \multicolumn{6}{|l|}{ Neonatal characteristics, $\mathrm{n}(\%)$} \\
\hline Gestational age (weeks) & & & & & 0.27 \\
\hline $24-25$ & $30(9.8)$ & $75(10.9)$ & $90(10.2)$ & $156(13.3)$ & \\
\hline $26-27$ & $62(24.1)$ & $156(26.4)$ & $192(25.8)$ & $274(27.0)$ & \\
\hline $28-30$ & $151(66.1)$ & $321(62.7)$ & $418(64.0)$ & $522(59.7)$ & \\
\hline Male Sex & $114(46.3)$ & $293(53.6)$ & $389(55.5)$ & $501(53.0)$ & 0.11 \\
\hline Small for Gestational Age ${ }^{\mathfrak{f}}$ & $91(38.2)$ & $201(37.3)$ & $241(35.5)$ & $313(33.9)$ & 0.47 \\
\hline Admission temperature $\left({ }^{\circ} \mathrm{C}\right)$ & & & & & 0.007 \\
\hline$<36$ & $84(37.3)$ & $173(31.3)$ & $197(30.6)$ & $247(26.0)$ & \\
\hline $36-37.9$ & $130(61.3)$ & $352(67.0)$ & $425(68.3)$ & $641(72.0)$ & \\
\hline$\geq 38$ & $3(1.4)$ & $8(1.6)$ & $7(1.1)$ & $18(2.0)$ & \\
\hline Doses of surfactant $(<28$ weeks $)$ & & & & & 0.007 \\
\hline 0 & $11(13.6)$ & $9(5.0)$ & $19(8.0)$ & $20(5.1)$ & \\
\hline 1 & $54(62.6)$ & $145(67.7)$ & $142(54.7)$ & $254(63.8)$ & \\
\hline 2 & $20(23.6)$ & $62(27.4)$ & $99(37.3)$ & $126(31.0)$ & \\
\hline Postnatal transfer & & & & & 0.001 \\
\hline 0 & $173(72.8)$ & $310(56.7)$ & $388(56.0)$ & $508(54.0)$ & \\
\hline 1 & $48(20.7)$ & $158(30.6)$ & $234(34.7)$ & 357 (38.9) & \\
\hline$\geq 2$ & $16(6.5)$ & $74(13.2)$ & $65(9.3)$ & $68(7.1)$ & \\
\hline
\end{tabular}

* Annual number of admissions of newborns under 31 weeks.

${ }^{\mathfrak{E}}$ Small for gestational age was defined as birth weight $<10^{\text {th }}$ percentile for gestational age and sex based on French intrauterine EPOPé curves (EGO et al 2016). 
Table 5: Live birth outcomes according to hospital volume, using logistic regression GEE model.

\begin{tabular}{|c|c|c|c|c|c|}
\hline \multirow[b]{2}{*}{ Outcomes } & \multirow[b]{2}{*}{ Method } & \multicolumn{4}{|c|}{ Hospital volume ${ }^{*}$} \\
\hline & & $\begin{array}{l}<55(\mathrm{Q} 1) \\
\mathrm{N}=243\end{array}$ & $\begin{array}{l}55-79(\mathrm{Q} 2) \\
\mathrm{N}=552\end{array}$ & $\begin{array}{c}80-109(\mathrm{Q} 3) \\
\mathrm{N}=700\end{array}$ & $\begin{array}{c}\geq 110(\mathrm{Q} 4) \\
\mathrm{N}=952\end{array}$ \\
\hline \multicolumn{6}{|l|}{ Survival at discharge } \\
\hline$\%(95 \% \mathrm{CI})$ & $\mathrm{CC}$ & $85.7(81.5-89.9)$ & $88.1(85.4-90.7)$ & $87.5(85.2-89.9)$ & $88.6(86.7-90.5)$ \\
\hline adjusted OR $[95 \% \mathrm{CI}]^{\mathfrak{f}}$ & & $0.56[0.33-0.91]$ & $0.90[0.57-1.43]$ & $0.81[0.55-1.20]$ & 1 \\
\hline \multicolumn{6}{|c|}{$\begin{array}{l}\text { Survival without severe neonatal } \\
\text { morbidity }\end{array}$} \\
\hline$\%(95 \% \mathrm{CI})$ & MI & $72.4(66.5-78.2)$ & $73.8(69.4-78.3)$ & $65.2(54.3-76.0)$ & $70.3(64.7-75.9)$ \\
\hline adjusted OR $[95 \% \mathrm{CI}]^{\mathfrak{f}}$ & & $0.80[0.50-1.26]$ & $1.04[0.70-1.53]$ & $0.71[0.48-1.03]$ & 1 \\
\hline \multicolumn{6}{|c|}{$\begin{array}{l}\text { Survival without neuromotor or sensory } \\
\text { disabilities at } 2 \text { years corrected age. }\end{array}$} \\
\hline$\%(95 \% \mathrm{CI})$ & MI & $75.0(54.6-95.3)$ & $76.7(58.9-94.5)$ & $77.8(60.1-95.6)$ & 80.7 (67.5-93.9) \\
\hline adjusted OR $[95 \% \mathrm{CI}]^{\mathfrak{f}}$ & & $0.60[0.38-0.95]$ & $0.79[0.51-1.21]$ & $0.83[0.58-1.20]$ & 1 \\
\hline
\end{tabular}

CC: complete (fully documented) cases. MI: available cases after multiple imputation.

* Annual number of admissions of newborns under 31 weeks.

${ }^{£}$ Adjusted for gestational age, sex, small for gestational age, multiple pregnancy, maternal age, infertility treatment, principal cause of prematurity, parental socioeconomic status and mother's country of birth. 


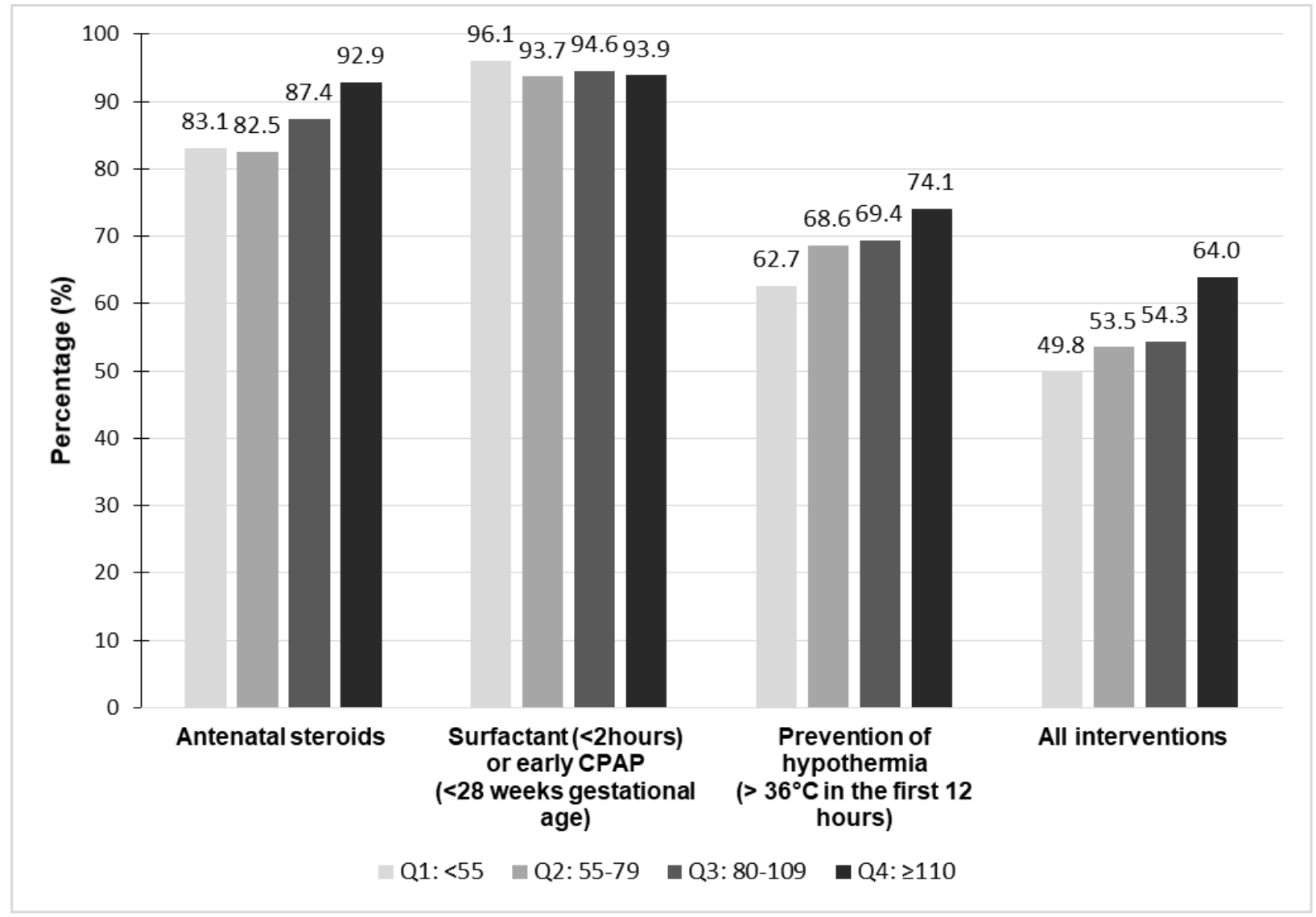


Table 1: Comparison of characteristics among responders and non-responders

\begin{tabular}{|c|c|c|c|}
\hline & \multicolumn{2}{|c|}{$\begin{array}{l}\text { Survivors at } 2 \text { years CA eligible for the study } \\
\text { Neuromotor and sensory disabilities data available }\end{array}$} & \multirow[b]{2}{*}{ p-value } \\
\hline & $\begin{array}{c}\text { Yes } \\
\mathrm{n}=1764\end{array}$ & $\begin{array}{c}\text { No } \\
\mathrm{n}=339\end{array}$ & \\
\hline \multicolumn{4}{|l|}{ Maternal characteristics, n (\%) } \\
\hline Maternal age (years) & & & 0.0001 \\
\hline$<25$ & $274(15.6)$ & $104(30.2)$ & \\
\hline $25-34$ & $1076(60.9)$ & $163(48.0)$ & \\
\hline$\geq 35$ & $414(23.5)$ & $72(21.8)$ & \\
\hline Mother born outside of France & $364(22.3)$ & $90(29.5)$ & 0.007 \\
\hline Socio-economic status & & & 0.0001 \\
\hline Professional/ Intermediate & $767(45.3)$ & $75(25.7)$ & \\
\hline Other & $877(52.0)$ & $202(66.8)$ & \\
\hline Not employed & $46(2.7)$ & $22(7.4)$ & \\
\hline Multiple pregnancy & $589(33.3)$ & $101(29.4)$ & 0.15 \\
\hline Antenatal transfer & $989(56.5)$ & $216(63.8)$ & 0.01 \\
\hline Infertility treatment & $339(19.4)$ & $41(12.5)$ & 0.003 \\
\hline Doses of antenatal steroids & & & 0.02 \\
\hline 0 & $183(10.7)$ & $48(14.1)$ & \\
\hline 1 & $263(15.4)$ & $35(10.5)$ & \\
\hline 2 & $1259(73.9)$ & $244(75.4)$ & \\
\hline Principal cause of preterm delivery & & & 0.09 \\
\hline Preterm labor & $656(36.5)$ & $114(33.3)$ & \\
\hline pPROM & $475(26.5)$ & $108(31.1)$ & \\
\hline $\begin{array}{l}\text { Hypertensive disorders or Placental } \\
\text { abruption }\end{array}$ & $413(24.1)$ & 64 (19.8) & \\
\hline Fetal Growth Retardation & $105(6.3)$ & $21(6.6)$ & \\
\hline Other circumstances & $115(6.6)$ & $32(9.2)$ & \\
\hline Cesarean delivery & $1210(70.0)$ & $205(63.0)$ & 0.01 \\
\hline \multicolumn{4}{|l|}{ Neonatal characteristics, $n(\%)$} \\
\hline Gestational age (weeks) & & & 0.4 \\
\hline $24-25$ & $170(7.6)$ & $36(8.4)$ & \\
\hline $26-27$ & $465(24.5)$ & $85(23.2)$ & \\
\hline $28-30$ & $1129(67.9)$ & $218(68.5)$ & \\
\hline Male Sex & $946(53.8)$ & $162(47.8)$ & 0.04 \\
\hline Small for Gestational Age & $609(35.2)$ & $116(35.4)$ & 0.9 \\
\hline Admission temperature $\left({ }^{\circ} \mathrm{C}\right)$ & & & 0.76 \\
\hline$<36$ & $478(27.6)$ & $89(27.1)$ & \\
\hline $36-37.9$ & $1180(70.7)$ & $224(70.6)$ & \\
\hline$\geq 38$ & $27(1.7)$ & $7(2.3)$ & \\
\hline Doses of surfactant (<28weeks) & & & 0.10 \\
\hline 0 & $482(29.3)$ & $110(35.2)$ & \\
\hline 1 & $946(53.8)$ & $164(49.6)$ & \\
\hline 2 & $305(16.9)$ & $54(15.2)$ & \\
\hline Severe neonatal morbidities & $32(18.3)$ & $65(19.5)$ & 0.62 \\
\hline Hospital volume, n (\%) & & & 0.001 \\
\hline$<55$ & $157(9.1)$ & $47(14.1)$ & \\
\hline $55-79$ & $395(22.3)$ & $79(23.2)$ & \\
\hline 80-109 & $485(27.8)$ & $114(33.7)$ & \\
\hline$\geq 110$ & $727(40.8)$ & $99(29.0)$ & \\
\hline
\end{tabular}


Table 2: Hospital characteristics according to hospital volume.

\begin{tabular}{ccccc}
\hline \multicolumn{1}{c}{ Hospital characteristics (n=66) } & \multicolumn{4}{c}{ Hospital volume* } \\
& $<55$ & $54-79$ & $80-109$ & $\geq 110$ \\
& $\mathrm{n}=17$ & $\mathrm{n}=17$ & $\mathrm{n}=17$ & $\mathrm{n}=15$ \\
& $(26 \%)$ & $(26 \%)$ & $(26 \%)$ & $(23 \%)$ \\
\hline University hospital, n (\%) & $3(18.0)$ & $9(53.0)$ & $12(70.0)$ & $13(87.0)$ \\
Type of surgery available ${ }^{\mathrm{f}}, \mathrm{n}(\%)$ & & & & \\
0 & $10(58.8)$ & $7(41.1)$ & $4(23.5)$ & $3(20.0)$ \\
$\geq 1$ & $7(41.8)$ & $10(58.6)$ & $13(76.5)$ & $12(80.0)$ \\
$\begin{array}{l}\text { Number of neonatal resuscitation beds, } \\
\text { mean/ median }\end{array}$ & $6.2 / 6.0$ & $9.3 / 8.0$ & $11.9 / 12.0$ & $14.6 / 15.0$ \\
\hline
\end{tabular}

* Annual number of admissions of newborns under 31 weeks.

${ }^{£}$ Ability to perform at least one of the following interventions; laparotomy for NEC, patent ductus arteriosus ligation, insertion of ventriculo-peritoneal shunt. 
Table 6: Association between hospital volume and severe neonatal morbidity.

\begin{tabular}{|c|c|c|c|c|c|c|c|}
\hline \multirow[b]{2}{*}{ Outcomes } & \multicolumn{4}{|c|}{ Hospital volume* } & \multirow[b]{2}{*}{ Total } & \multirow[b]{2}{*}{$p$} & \multirow[b]{2}{*}{$\begin{array}{l}\text { Missing } \\
\text { data }(\%)\end{array}$} \\
\hline & $\begin{array}{c}<55 \\
\mathrm{~N}=243(10.1 \%)\end{array}$ & $\begin{array}{c}55-79 \\
\mathrm{~N}=552(22.6 \%)\end{array}$ & $\begin{array}{c}80-109 \\
\mathrm{~N}=700(28.8 \%)\end{array}$ & $\begin{array}{c}\geq 110 \\
\mathrm{~N}=952(38.5 \%)\end{array}$ & & & \\
\hline $\begin{array}{l}\text { Severe neonatal morbidity } \\
\mathrm{N}=2116, \mathrm{n} / \mathrm{N}(\%)\end{array}$ & $32 / 198(14.5)$ & $75 / 463(14.8)$ & $115 / 520(21.2)$ & $151 / 776(18.5)$ & $373 / 1957$ & 0.02 & 7.5 \\
\hline BPD & $16 / 200(7.0)$ & $47 / 463(9.0)$ & $49 / 528(8.4)$ & 78/788 (9.2) & $190 / 1979$ & 0.74 & 6.9 \\
\hline cPVL or IVH (III/ IV) & $13 / 204(6.0)$ & $23 / 480(4.5)$ & $44 / 602(7.1)$ & 45/830 (4.8) & $125 / 2116$ & 0.24 & 0 \\
\hline NEC (II or III) & $5 / 203(2.1)$ & 8/ 477 (1.6) & $36 / 588(6.2)$ & 29/822 (3.6) & $78 / 2090$ & 0.003 & 1.2 \\
\hline ROP & $4 / 202(1.5)$ & $6 / 479(1.0)$ & $7 / 592(1.0)$ & 18/824 (1.9) & $35 / 2097$ & 0.31 & 1.0 \\
\hline Crude OR & $1.00[0.63-1.60]$ & $0.89[0.60-1.33]$ & $1.35[0.87-2.10]$ & 1 & & & \\
\hline Adjusted $\mathrm{OR}^{£}$ & $1.21[0.72-2.08]$ & $0.93[0.59-1.45]$ & $1.44[0.81-2.56]$ & 1 & & & \\
\hline
\end{tabular}

* Annual number of admissions of newborns under 31 weeks.

${ }^{\$}$ At least one of these diseases: BPD, severe bronchopulmonary dysplasia; IVH, severe intraventricular hemorrhage cPVL, cystic periventricular leukomalacia; NEC, necrotizing enterocolitis; ROP, retinopathy of prematurity.

Missing data $=159$.

${ }^{£}$ Adjusted for gestational age, sex, small for gestational age, multiple pregnancy, maternal age, infertility treatment, principal cause of prematurity, parental socioeconomic status and mother's country of birth. 
Table 7: Sensitivity analysis

\begin{tabular}{|c|c|c|c|c|c|c|}
\hline \multirow[t]{2}{*}{ Outcomes } & \multirow[t]{2}{*}{ Method } & \multicolumn{4}{|c|}{ Hospital volume* } & \multirow[t]{2}{*}{ Total } \\
\hline & & $<55$ & $55-79$ & 80-109 & $\geq 110$ & \\
\hline \multicolumn{7}{|c|}{$\begin{array}{l}\text { Survival without neuromotor or } \\
\text { sensory disabilities at } 2 \text { years } \\
\text { corrected age in infants born } \\
\text { between } 26 \text { and } 30 \mathrm{WG} \text {. }\end{array}$} \\
\hline $\mathrm{N}$ & & 213 & 477 & 610 & 796 & 2096 \\
\hline$\%(95 \% \mathrm{CI})$ & MI & $77.9(60.9-94.9)$ & $80.2(67.2-93.0)$ & $82.3(70.7-93.9)$ & $85.1(75.9-94.2)$ & \\
\hline adjusted OR $[95 \% \mathrm{CI}]^{£}$ & MI & $0.57[0.36-0.90]$ & $0.69[0.44-1.07]$ & $0.80[0.55-1.16]$ & 1 & \\
\hline \multirow{2}{*}{\multicolumn{7}{|c|}{$\begin{array}{l}\text { Survival without neuromotor or } \\
\text { sensory disabilities at } 2 \text { years } \\
\text { corrected age in metropolitan } \\
\text { France }\end{array}$}} \\
\hline & & & & & & \\
\hline $\mathrm{N}$ & & 216 & 493 & 613 & 952 & 2274 \\
\hline$\%(95 \% \mathrm{CI})$ & MI & $75.0(54.6 .6-95.3)$ & $76.7(58.9-94.5)$ & $77.9(60.2-95.6)$ & $80.7(67.5-93.8)$ & \\
\hline adjusted OR $[95 \% \mathrm{CI}]^{£}$ & MI & $0.59[0.37-0.96]$ & $0.78[0.49-1.24]$ & $0.87[0.59-1.27]$ & 1 & \\
\hline
\end{tabular}

* Annual number of admissions of newborns under 31 weeks.

MI: available cases after multiple imputations.

${ }^{£}$ Adjusted for gestational age, sex, small for gestational age, multiple pregnancy, maternal age, infertility treatment, principal cause of prematurity, parental socioeconomic status and mother's country of birth. 
Table 8: Survivor outcomes at 2 years corrected age according to hospital volume, using logistic regression GEE model.

\begin{tabular}{|c|c|c|c|c|c|}
\hline \multirow{3}{*}{ Outcomes } & \multirow{3}{*}{ Method } & \multicolumn{4}{|c|}{ Hospital volume $^{*}$} \\
\hline & & \multirow{2}{*}{$\begin{array}{l}<55(\mathrm{Q} 1) \\
\mathrm{N}=204\end{array}$} & \multirow{2}{*}{$\begin{array}{c}55-79(\mathrm{Q} 2) \\
\mathrm{N}=474\end{array}$} & \multirow{2}{*}{$\begin{array}{c}80-109(\mathrm{Q} 3) \\
\mathrm{N}=599\end{array}$} & \multirow{2}{*}{$\begin{array}{c}\geq 110(\mathrm{Q} 4) \\
\mathrm{N}=826\end{array}$} \\
\hline & & & & & \\
\hline \multicolumn{6}{|c|}{ Neuromotor and sensory disabilities } \\
\hline$\%(95 \% \mathrm{CI})$ & $\mathrm{CC}$ & $4.2(1.0-7.5)$ & $4.8(2.6-7.0)$ & $3.1(1.5-4.7)$ & $3.0(1.7-4.3)$ \\
\hline adjusted OR $[95 \% \mathrm{CI}]^{£}$ & & $1.56[0.58-4.20]$ & $1.81[0.87-3.79]$ & $1.06[0.55-2.03]$ & 1 \\
\hline$\%(95 \% \mathrm{CI})$ & MI & $4.6(1.3-7.9)$ & $5.2(2.8-7.5)$ & $3.3(1.7-5.0)$ & $3.3(1.9-4.7)$ \\
\hline adjusted OR $[95 \% \mathrm{CI}]^{£}$ & & $1.48[0.56-3.93]$ & $1.73[0.85-3.57]$ & $1.05[0.56-1.97]$ & 1 \\
\hline \multicolumn{6}{|c|}{ ASQ score below threshold at 2 years } \\
\hline$\%(95 \% \mathrm{CI})$ & $\mathrm{CC}$ & $46.5(37.2-55.9)$ & $44.7(38.7-50.8)$ & $43.5(38.0-48.3)$ & $40.6(36.3-44.9)$ \\
\hline adjusted OR $[95 \% \mathrm{CI}]^{£}$ & & $1.39[0.82-2.37]$ & $1.06[0.75-1.50]$ & $0.97[0.72-1.32]$ & 1 \\
\hline$\%(95 \% \mathrm{CI})$ & MI & $49.9(41.4-58.4)$ & $49.6(44.2-55.0)$ & $47.4(42.7-52.1)$ & $45.9(41.9-49.9)$ \\
\hline adjusted OR $[95 \% \mathrm{CI}]^{£}$ & & $1.37[0.88-2.14]$ & $1.00[0.70-1.42]$ & $0.99[0.74-1.33]$ & 1 \\
\hline
\end{tabular}

$\overline{\mathrm{CC}}$ : complete (fully documented) cases. MI: available cases after multiple imputation. * Annual number of admissions of newborns under 31 weeks. ${ }^{£}$ Adjusted for gestational age, sex, small for gestational age, multiple pregnancy, maternal age, infertility treatment, principal cause of prematurity, parental socioeconomic status and mother's country of birth. ${ }^{\mathfrak{x}}$ Infants with cerebral palsy, deafness, blindness were excluded. 
2926 live-born neonates at 24-30 weeks of gestation (WG) with parental consent at birth

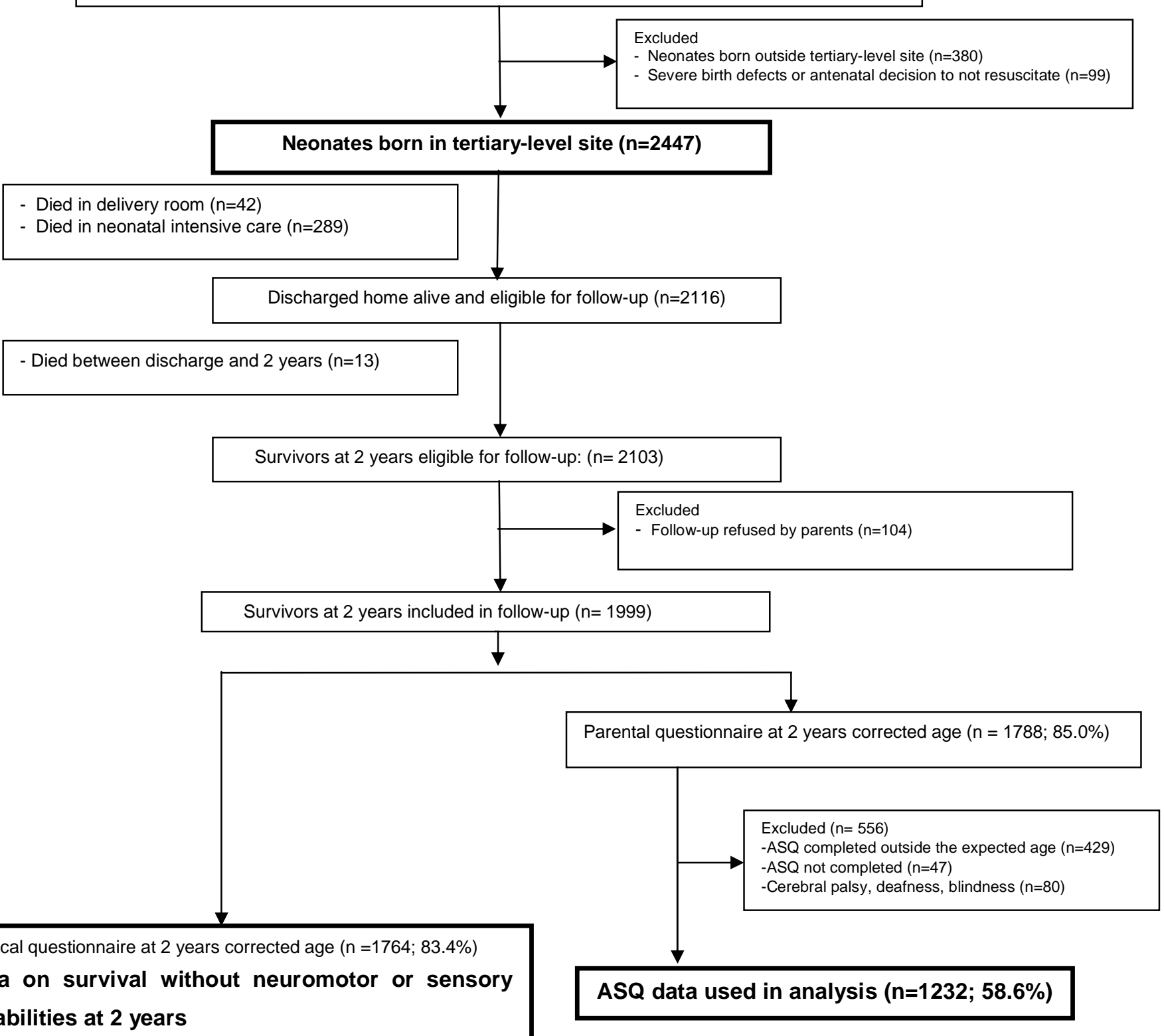

